\title{
Teenage pregnancy and implications on child survival amongst mothers attending a clinic in the East-End, Freetown, Sierra Leone*
}

\author{
Tamramat I. Runsewe-Abiodun", Sahr F. Bondi
}

Ola during Children's Hospital, Freetown, Sierra Leone

Email: "dr_abiodun@yahoo.com

Received 22 August 2013; revised 16 September 2013; accepted 23 September 2013

Copyright (C) 2013 Tamramat I. Runsewe-Abiodun, Sahr F. Bondi. This is an open access article distributed under the Creative Commons Attribution License, which permits unrestricted use, distribution, and reproduction in any medium, provided the original work is properly cited.

\begin{abstract}
Introduction: Every year it is estimated that about 14 million adolescent girls give birth globally with the highest rate (143 per 1000 girls aged 15 - 19 years) in the sub-Saharan Africa. Babies born to adolescent mothers are at greater risk and are far more likely to die than those born to older women. This study therefore sets out to describe the health care seeking behaviors in a cohort of teenage mothers attending an Under-Five Clinic in a densely populated section of Freetown, Sierra Leone with a view of determining the impact of their behavior on the survival of their children. Methodology: This is a descriptively cross sectional and prospective study that involved four hundred and six mothers attending the Under-Five Clinic in the Eastern end of Freetown using semiclosed ended questionnaire which were interviewers administered between $1^{\text {st }}$ and $29^{\text {th }}$ July 2011. Result: The age of the study population ranged between 12 and 45 years, with a mean of $24.8 \pm 6.3$ years. Of the four hundred and six, eighty nine $(21 \%)$ were teenagers (less than 20 years) with a majority $(60.6 \%)$ of them being between 18 and 19 years old. Concerning the 89 teenage mothers in the study population, the majority $(95.5 \%)$ did not possess the secondary school education, $42.7 \%$ were petty traders and more than a half of them $(61.8 \%)$ were married. The mothers were rated low in all the activities geared towards child survival except immunization. In addition there was a delay in the initiation of complementary feeds which were also of poor quality. Fewer
\end{abstract}

*Disclosure: the authors declare no special interest.

Authors' contribution: TIR conceived the study and wrote the initial draft. SF read through for intellectual content and clarity. Both authors prepared and agreed on the final content of the manuscript.

\#Corresponding author. percentages of the mothers who had antenatal care in the hospitals delivered there. Conclusion: This study has revealed that early marriage is still common in Sierra Leone. Also the teenage mothers did not engage fully in a majority of activities that have been proven to contribute to the survival of babies in the Tropics thereby making their children vulnerable to malnutrition, measles and diarrhoeal diseases. It was recommended that the country should use recognised teenage programs aimed at urgently addressing a reduction in teenage pregnancy especially by improving the provision of education/vocational studies for the girl child.

Keywords: Teenage Pregnancy; Under-Five Mortality; Freetown

\section{INTRODUCTION}

The definition of a teenager is as varied as who is an adolescent. Generally, teenage pregnancy is considered as that occurring between thirteen and eighteen years of age. Occasionally girls as young as ten who are sexually active could become pregnant.

Every year it is estimated that about 14 million adolescent girls give birth globally [1] with the highest rate (143 per 1000 girls aged 15 - 19 years) in the sub-Saharan Africa [2]. It is also believed that women in Africa generally get married at earlier ages than elsewhere leading to early pregnancies [3].

Teenage pregnancy is beginning to attract significant interest among researchers, political and religious leaders, social scientists and commentators as a result of its complexity, health and social implications.

The association between teenage pregnancy and social disadvantage is global [4-7] and the continuing appre- 
hension about teenage pregnancy is based on the profound impact that teenage pregnancy can have on the health of the girls and their children. Africa faces some of the most daunting public health problems in the world and to meet the Millennium Development Goals, African countries therefore need to reduce teenage pregnancy [8].

In Sierra Leone, the 2008 DHS Survey revealed that 16 percent of pregnant women between 15 and 49 years were married before the age of 15 years and about a half before 18 years. A majority of them are in the poorest wealth quintile [9].

It is agreed that babies born to adolescent mothers are at greater risk. A review found that adolescent pregnancies are associated with premature delivery, still birth, fetal distress, birth asphyxia, low birth weight and miscarriages. Also, babies born to teen mothers are also far more likely to die than those born to older women [10].

This study therefore sets out to describe the health care seeking behaviors in a cohort of teenage mothers attending an Under-Five Clinic in a densely populated region of Freetown, Sierra Leone with a view to determining the impact of their behavior on the survival of their children.

\section{METHODOLOGY}

This is a descriptive cross sectional prospective study that involved a cohort of mothers (four hundred and six) attending the under-five clinic in the Eastern end of Freetown.

Freetown is the socio and economic nerve centre of Sierra-Leone. It is the capital and largest city. The city of Freetown is politically divided into three "ends"; eight municipalities or wards. The East End of Freetown has three wards: East I, East II, and East III; the Central Freetown includes two wards: Central I and Central II and the West End of Freetown contain the wards West I, West II, and West III. The wards in the East End of Freetown are the most densely populated and are inhabited by the poorest in the city. The estimated population of Freetown is 773,000 [9].

Mothers attending the clinic were consecutively recruited into the study between $1^{\text {st }}$ July and 29 $9^{\text {th }}$ July 2011. Semi-closed ended questionnaire were interviewer administered.

Permission for the study was obtained from the medical superintendent of the Ola during Children's Hospital to which the under-five clinic is affiliated and a written informed consent also obtained from the prospective study subjects.

Data included in the questionnaire were information on the bio data, socio-economic status of mother, sexuality issues and other maternal information that may affect the health of the child e.g. family planning choices, number of children, child health care seeking and prac- tices, family planning, pattern of breastfeeding, attendance at Antenatal clinic, growth monitoring for the index child, knowledge about ORS etc. The index child bio data, immunization status, anthropometric parameter, and 24-hour dietary were recalled.

The nutritional status was determined based on the Gomez classification [11].

Data entry, validation and analysis were done using Epi-info 3.5.3 software. Frequency tables were generated for all the categorical variables and association between them was tested using the chi-square test. Means and standard deviations and other descriptive measures were determined for quantitative variables such as age, parity, etc. Level of significance was set at p value $<0.05$.

\section{RESULT}

- A total of 406 mothers attending the clinic were consecutively recruited into the study. The age of the study population ranged between 12 and 45 years, with a mean of $24.8 \pm 6.3$ years. Over $40.5 \%$ of the study population had their first child as teenager. Age of first sexual contact in the study population ranged between 10 - 18 years. There was a significant positive correlation between the time of first sexual contact and first child correlation coefficient was 0.99 and $\mathrm{p}$ value of 0.0000 .

Socio-demographic characteristics of the teenage $\underline{\text { mothers }}$

- Of the four hundred and six, eighty nine (21\%) were teenagers (less than 20 years) with a majority (60.6\%) of them being between 18 and 19 years old. The age range of the teenage mothers ranged between 12 and 19 years. The mean age of the teenage mothers was $17.5 \pm 1.6$ years. They reside mainly in the eastern end of Freetown (85.4\%). Over two-thirds of the mothers (77.5\%) were Moslems, 19.1\%, Christians and $3.3 \%$ were traditional believers.

- Concerning the 89 teenage mothers in the study population, the majority (95.5\%) did not possess the secondary school certificate; 44(49.4\%) did not go beyond secondary education, 34(38.2\%) had no formal education and $8(9.0 \%)$ had primary education. Majority of them were petty traders (42.7\%), the others were students, artisans or unemployed. More than a half of them (61.8\%) were married. This was the first pregnancy in a majority, 72(80.9\%), of the teenage mothers. Table 1 depicts the socio-demographic characteristics of the teenage mothers in the study population.

Child survival activities among the teenage mothers

As shown in Table 2, slightly more than a half (65.9\%) of the teenage mothers take their children for growth monitoring and about a quarter $(25.3 \%)$ of them can correctly prepare ORS. This activity is significantly differ- 
Table 1. Socio-demographic characteristics of the teenage mothers.

\begin{tabular}{|c|c|c|c|}
\hline Variables & & & \\
\hline Age (years) & Frequency & Percent & Cum percent \\
\hline 12 & 1 & $1.1 \%$ & $1.1 \%$ \\
\hline 13 & 1 & $1.1 \%$ & $2.2 \%$ \\
\hline 14 & 1 & $1.1 \%$ & $3.4 \%$ \\
\hline 15 & 7 & $7.9 \%$ & $11.2 \%$ \\
\hline 16 & 15 & $16.9 \%$ & $28.1 \%$ \\
\hline 17 & 10 & $11.2 \%$ & $39.3 \%$ \\
\hline 18 & 19 & $21.3 \%$ & $60.7 \%$ \\
\hline 19 & 35 & $39.3 \%$ & $100.0 \%$ \\
\hline Religion & Frequency & Percent & Cum percent \\
\hline Islam & 69 & $77.5 \%$ & $77.5 \%$ \\
\hline Christianity & 17 & $19.1 \%$ & $96.6 \%$ \\
\hline Traditional & 3 & $3.3 \%$ & $98.9 \%$ \\
\hline Education & Frequency & Percent & Cum percent \\
\hline Tertiary & 1 & $1.1 \%$ & $1.1 \%$ \\
\hline Post secondary & 2 & $2.2 \%$ & $3.4 \%$ \\
\hline Secondary & 44 & $49.4 \%$ & $52.8 \%$ \\
\hline Primary & 8 & $9.0 \%$ & $61.8 \%$ \\
\hline Non formal & 34 & $38.2 \%$ & $100.0 \%$ \\
\hline Occupation & Frequency & Percent & Cum percent \\
\hline Junior civil servant & 3 & $3.3 \%$ & $4.5 \%$ \\
\hline Artisan & 8 & $9.0 \%$ & $12.4 \%$ \\
\hline Petty traders & 38 & $42.7 \%$ & $55.1 \%$ \\
\hline Students & 22 & $24.7 \%$ & $79.8 \%$ \\
\hline Unemployed & 18 & $20.2 \%$ & $100.0 \%$ \\
\hline \multicolumn{4}{|l|}{ Marital status } \\
\hline Married & 55 & $61.8 \%$ & $61.8 \%$ \\
\hline Single & 33 & $37.1 \%$ & $98.9 \%$ \\
\hline Separated & 1 & $1.1 \%$ & $100.0 \%$ \\
\hline
\end{tabular}

ent when compared with that of older mothers ( $\mathrm{p}$ value $=$ 0.04)

All mothers breast fed their babies. Breast milk was the first drink in $72(80.9 \%)$ of the babies, out of which breast milk was offered in 26 within the first 30 minutes of life. Only 11 out of the 53 mothers (20.9\%) whose ba-
Table 2. Child survival activities by the teenage mothers.

\begin{tabular}{ccc}
\hline Child survival activities & Yes & No \\
\hline Growth monitoring & $58(65.9)$ & $30(34.1)$ \\
Preparation of ORS & $23(25.4)$ & $53(59.6)$ \\
Exclusive breastfeeding & $11(20.8 \%)^{*}$ & $42(79.2)$ \\
Appropriate complimentary feeds & $25(47.2)^{*}$ & $28(52.8)$ \\
\hline Immunization & & \\
\hline Complete for BCG & $86(96.6)$ & $3(3.4)$ \\
Complete for pentavalent & $76(85.4)$ & $13(14.6)$ \\
OPV & $62(69.7)$ & $27(30.3)$ \\
Measles & $40(44.9)$ & $49(55.1)$ \\
Yellow fever & $28(31.5)$ & $61(68.5)$ \\
Use of any family planning method & $13(14.7)$ & $76(86.3)$ \\
Appropriate ANC & $72(80.9)$ & $17(19.1)$ \\
Knowledge of HIV status & $68(76.4)$ & $21(23.6)$ \\
Outcome of HIV test & $59(66.3)$ & $30(33.7)$ \\
\hline
\end{tabular}

*Total number of respondents was 53; Figures in bracket are percentages of total.

bies were older than 6 months breastfed exclusively. Water and Oral Rehydration salt solution were the major additives to breastfeeding in the first six months of life.

Complimentary feeds were commenced between 1 and 24 months. Mean age of commencement of complementary feed was $7.25 \pm 3.81$ months. A quarter of the teenage mothers started complimentary feeds earlier than 6 months, similar number at 6 months and the remaining half after the age of 6 months. More than a half of the babies were weaned on inappropriate diets; mainly ricepap (15/53), pap (3/53), rice (7/53) and tea and bread (3/53). The rest were weaned on Benni-mix (9/53) were weaned on a locally available complementary feed "Bennimix" which is a combination of pigeon peas, sesame, rice and sugar) and Nutrilac/Tinned cereal (16/53).

Almost all the babies (96.6\%) of the teenage mothers had Bacille Calmette Guerin vaccine (BCG), 85.4\% had Pentavalent, OPV was taken by $69.7 \%, 44.9 \%$ had measles vaccine, and $31.5 \%$ had yellow fever vaccine. For those who were not able to complete their immunization, major reason was non-availability of the vaccines in the clinic as at the time that the baby was due for the vaccine. Table 2 shows the activities geared toward child survival by the teenage mothers in the study population

There was no statistically significant difference between the number of teenagers and the entire study population in their access of family planning. Although $72.4 \%$ of the study population were not using any form of FP, $85.2 \%$ were not using any FP method among the 
teenage mothers. This difference was not statistically significant. Amongst those using any form of family planning method, Depo-Provera is preferred in $10.2 \%$ and condom in $0.5 \%$. There was a significant association ( $p=0.04$ ) between the ages when the respondents had the first child and FP preference. Table 3 indicates the family planning preference among the teenagers.

Of the $80.9 \%$ of the teenagers who had Antenatal Care (ANC) in the Govt. hospital only 66.3\% delivered in the hospitals. Although only $19.1 \%$ did not have any form of ANC, more of them (28\%) delivered at home/TBAs.

The age range of babies of the teenage mothers was between 1 and 60 months, mean $10.4 \pm 9.3$ months. Although the percentage weight for age (\%WFA) of the babies of the teenage mothers was not statistically significantly different from that of the matured mothers, 91\% of their children were malnourished (Gomez classification). There was a positive correlation between the ages of the mothers and the nutritional status of the babies $(r=0.73)$.

Mean episode of diarrhea/child/month among the teenage mothers was $1.9 \pm 1.98 /$ month. There was no statistically significant difference between this and babies of matured mothers. $\mathrm{p}$ value $=0.2$.

Majority of the teenage mothers will take steps when their babies are sick with fever or diarrhea e.g. take babies to Government hospital, give Oral Rehydration Salt Solutions (ORS) and drugs when ill but $12.5 \%$ will do nothing.

Only sixty-eight of the teenage mothers (76.4\%) know their HIV status, the rest do not know. It was negative in 59(66.3\%) and the rest were not sure.

\section{DISCUSSION}

This study has identified that one out of every five mothers attending the clinic delivered babies before the age of 20 and the majority of them being between 18 and 19 years. Almost two-thirds of the teenage mothers were married. This is in line with reports from Demographic Health Survey in the country [9]. This experience is supported by earlier observations that women in Africa

Table 3. Family planning choice of the study population.

\begin{tabular}{ccc}
\hline Family Planning Choice & Frequency & Percentage \\
\hline Coil & 1 & 1.1 \\
Pills & 1 & 1.1 \\
Injection & 9 & 10.2 \\
None & 75 & 85.2 \\
Traditional & 2 & 2.3 \\
TOTAL & 88 & 100.0 \\
\hline
\end{tabular}

generally tend to marry earlier than elsewhere [3]. Hence, it will appear that teenage pregnancy in our community may not be largely accidental. However, the place of socio-economic perception of teenage pregnancy cannot be overlooked. It is possible that a majority of the parents married off the girls for reasons of relief of economic burden, social stigmatization, religious or cultural. This study did not determine whether the pregnancies were within or outside marriage.

In this study, 9 out of the 10 teenage mothers did not go beyond secondary school and were mainly either petty traders or unemployed. The inverse relationship between education and teenage pregnancy has been documented in other studies [12]. Female education has been found to be closely related to a more favourable life outcome for the child [13-15]. An educated female is more likely to access health care, be financially empowered to provide appropriate nutrient for her children, able to exercise her reproductive rights and thereby prevent unwanted pregnancy and properly space her family. The huge number of children in this report that are malnourished is therefore not unexpected. All the aforementioned factors will come into play to ensure the impairment of the nutritional status of the children of the teenage mother. Malnutrition alone or in combination with other disease conditions is associated with close to $54 \%$ of under-five mortality in the sub-region [16].

Change in the weight of the child is one of the earliest and most reliable means of determining the health of the child. This opportunity will be lost in those children who were not being taken to the clinic for growth monitoring. The resultant effect of this will be a delay in presentation at the health facility when the child is ill. In the Ola during Children's Hospital to which the clinic is affiliated, close to $90 \%$ of deaths in the Under-Five occur within 24 hours of admission into the hospital (unpublished data), majority of them being brought in a moribund state.

Dehydration is known to be the commonest cause of death from Diarrhoea. This can be prevented with appropriate use of Oral Rehydration Solution (ORS). In this study the babies were reported to have close to 2 episodes of diarrhea in a month. With the poor knowledge of preparation of ORS by a majority of the mothers, it can be expected that that these children may succumb to the effect of diarrhea.

Similar to other findings breastfeeding is a common practice amongst the teenage mothers in this study [17]. However, a majority of the babies of these teenage mothers were not exclusively breast fed. This may be arrogated to their low education and or ignorance about the benefit of breastfeeding. Lack of exclusive breastfeeding has also been observed to be a contributory factor to the development of malnutrition and the attendant health risks [18-20]. Also, in this study the teenage 
mothers commenced complimentary feeds much earlier and even at that the feeds were of poor quality. Although breastfeeding for a long period has been associated with better cognitive and language development in children [21], a delay in adding complementary feeds as being practiced by some of the teenage mothers have been associated with malnutrition [22].

The nutritional status of some of these children must have been evidently compromised by the recurring episodes of diarrhea and lack of exclusive breastfeeding. This study has found a strong positive correlation between the nutritional status of the children and the ages of the mothers. The implication is that with maturity in the age of the mothers a more favorable outcome can be expected in the child. Malnutrition is known to be a major contributor (54\%) to childhood deaths in the tropics [16].

A majority of the teenage mothers were not using any form of family planning; hence, there is a tendency for repeat pregnancy not adequately spaced with complications for the mother and implication for the health of the child.

\section{CONCLUSION}

This study has revealed that the teenage mothers that do not engage in a majority of activities have been proved to ensure the survival of their babies probably because of their low education. Therefore, it can be expected that their children will have a less favorable outcome with malnutrition, measles and diarrhoeal diseases, which are three of the major disease conditions associated with under-five mortality in the sub-region.

\section{RECOMMENDATIONS}

1) Teen pregnancy prevention programs e.g. use of mass media campaigns to promote safe sex.

2) A rise in school leaving age has been predicted to cut number of teenage pregnancies. This can be advocated in the country.

3) In as much as traditional and religious leaders preach abstinence, it may be more realistic that more effective birth control practice be advocated in teenagers as they are sexually active.

4) This study has revealed that the average age of first sexual contact is about 10 years in the country, hence primary school students must be educated about sex and sexuality and the consequences of pregnancy.

5) Bye laws and others to discourage child marriage. Cooperation of religious and traditional leaders will be needed in achieving this.

6) Support must be given to organizations aimed at provision of holistic approach to management of teenage pregnancy related issues; counselling, training, etc.

\section{ACKNOWLEDGEMENTS}

The Authors appreciate the assistance of Miss Martins and... in administering the questionnaires and the cooperation of the entire staff of Jenner-Wright Clinic, Freetown.

\section{REFERENCES}

[1] UNFPA (2013) State of world population 2004. www.unfpa.org/public/cache/offonce/home/publications/ $\mathrm{pid} / 2104$

[2] World Health Organization (2012) Adolescent pregnancy fact sheet No. 364.

www.who.int/mediacentre/factsheets/fs364/en/

[3] Bayisenge, J. (2013) Early marriage as a barrier to girl's education: A developmental challenge in Africa. www.ifuw.org/fuwa/docs/Early-marriage.pdf

[4] Holgate, H., Evans, R. and Yuen, F.K.O. (2006) Teenage pregnancy and parenthood: Global perspectives, issues and interventions. Routledge, New York.

[5] Harden, A., Brunton, G., Fletcher, A. and Oakley, A. (2009) Teenage pregnancy and social disadvantage: Systematic review integrating controlled trials and qualitative studies. British Medical Journal, 339, 1182-1185. http://dx.doi.org/10.1136/bmj.b4254

[6] Cherry, A.L., Byers, L. and Dillon, M.E. (2009) A global perspective on teen pregnancy. In: Ehiri, J., Ed., Maternal and Child Health: Global Challenges, Programs, and Policies, Springer, New York, 375-397. http://dx.doi.org/10.1007/b106524_21

[7] Jiang, N., Kolbe, L.J., Seo, D.-C., Kay, N.S. and Brindis, C.D. (2011) Health of adolescents and young adults: Trends in achieving the 21 critical national health objectives by 2010. Journal of Adolescent Health, 49, 124-132. http://dx.doi.org/10.1016/j.jadohealth.2011.04.026

[8] (2013) The linkages between the MDGs and young women's health.

http://www.youthcoalition.org/attachs/MH MDG factsh eet_webversion.pdf

[9] Sierra Leone demographic and health survey report 2008. www.meaasuredhs.com/pubs

[10] Reichman, N.E. and Pagnini, D.L. (1998) Maternal age and birth outcomes: Data from New Jersey. Family Planning Perspectives, 30, 127. http://dx.doi.org/10.2307/2991626

[11] Gomez, F. and Galvan, R.R. (2000) Mortality in $2^{\text {nd }}$ and $3^{\text {rd }}$ degree malnutrition. Bulletin of the World Health Organization, 78, 1275-1280.

[12] Gakidou, E., Cowling, K., Lozano, R. and Murray, C.J.L. (2010) Increased educational attainment and its effect on child mortality in 175 countries between 1970 and 2009: A systematic analysis. Lancet, 376, 959-974. http://dx.doi.org/10.1016/S0140-6736(10)61257-3

[13] Cleland, J.G. and van Ginneken, J.K. (1998) Maternal education and child survival in developing countries: The search for pathways of influence. Social Science and Medicine, 29, 1357-1368.

[14] Hobcarft, J. (1993) Women's education, child welfare 
and child survival: A review of evidence. Health Transition Review, 3, 159-175.

[15] UNICEF State of the World Children (2007) The link between child survival and women's empowerment. www.unicef.org/media

[16] UNICEF (2012) Nutrition report.

[17] Batal, M., Boulghourjian, C., Abdallah, A. and Afifi, R. (2006) Breast-feeding and feeding practices of infants in a developing country: A national survey in Lebanon. Public Health Nutrition, 9, 313-319. http://dx.doi.org/10.1079/PHN2006860

[18] Lamberti, L.M., Walker, C.L.F., Noiman, A., Victora, C. and Black, R.E. (2011) Breastfeeding and the risk for diarrhea morbidity and mortality. BMC Public Health, 11, S15-S27. http://dx.doi.org/10.1186/1471-2458-11-S3-S15

[19] Imdad, A., Yakoob, M.Y. and Bhutta, Z.A. (2011) Effect of breastfeeding promotion interventions on breastfeeding rates, with special focus on developing countries. BMC
Public Health, 11, S24-S32. http://dx.doi.org/10.1186/1471-2458-11-S3-S24

[20] Black, R.E., Allen, L.H., Bhutta, Z.A, Caulfield, L.E., de Onis, M., Ezzati, M., et al. (2008) Maternal and child undernutrition: Global and regional exposures and health consequences. The Lancet, 371, 243-260. http://dx.doi.org/10.1016/S0140-6736(07)61690-0

[21] Belfort, M.B., Rifas-Shiman, S.L., Kleinman, K.P., Guthrie, L.B., Bellinger, D.C., Taveras, E.M., Gillman, M.W. and Oken, E. (2013) Infant feeding and childhood cognition at ages 3 and 7 years: Effects of breastfeeding duration and exclusivity. JAMA Pediatrics, 167, Epub ahead of print.

[22] Agarwal, K.N. (2011) Weaning practices in other parts of the world: Case study India. Nestle Nutrition Workshop Series. Paediatric Programme, 68, 107-115. http://dx.doi.org/10.1159/000325670 